\title{
BUCKLING DELAMINATION IN COMPRESSED NO-TENSION HOMOGENEOUS BRITTLE BEAM-COLUMNS REINFORCED WITH FRP
}

\author{
Francesco Marchione \\ Università Politecnica delle Marche, Dipartimento di Ingegneria Civile, Edile e \\ Architettura (DICEA), Ancona, via Brecce Bianche 60131, Italy, \\ f.marchione@pm.univpm.it
}

\begin{abstract}
The main issue of this paper is the instability of no-tension structural members reinforced with FRP. This study concerns the instability of FRP reinforcement. The primary buckling problem of a compressed element involves the division of the deflected section into a compressed and a tensioned zone. In particular, in the case of a compressed slender element reinforced on both tense and compressed side FRP delamination phaenomenon could occur on the latter. This entails the loss of the reinforcement effectiveness in the compressed area for nominal load values much lower than material effective strength. Therefore, structural elements or portions thereof which absorb axial components in the direction of the reinforcement may exhibit relatively modest performance with respect to the unreinforced configuration. By employing a no-tension material linear in compression, an analytical solution for FRP buckling delamination length is provided. The main objective of this paper is to provide a simplified tool which allows to evaluate the critical load of the reinforced beamcolumn and to predict the tension at which delamination and the loss of effectiveness of reinforcement in the compressed area could occur.
\end{abstract}

\section{KEYWORDS}

Buckling analysis, FRP delamination, Compressed beam-columns, Composite beamcolumn, buckling composite delamination, FRP reinforced beam-columns

\section{INTRODUCTION}

Nowadays the use of FRP reinforcements for the consolidation of existing structures is becoming increasingly popular in the field of civil engineering [1], [2] thanks to their flexibility, ease, and speed of installation. They also have a high strength-to-weight ratio and add practically no mass to the structure [3], [4].

The use of FRP reinforcements allows providing the masonry panel with adequate tensile strength for stresses both bending in or out of the plane and shear in the plane [5] - [8].

However, it is observed that a structural element subject to seismic action undergoes the cyclic action of external forces. If we consider some common techniques of reinforcement (e.g. shear reinforcement of masonry panels, bending reinforcements of reinforced concrete beam-columns) it could be observed how these reinforcements are subjected to alternate cycles of tensile and compressive forces.

The case of axially loaded beam-columns is the simplest of the phenomena of elastic equilibrium instability, or of the balance between internal tensions and external forces. This case, studied by Euler in the mid-1700s, remained for over a century almost without any practical interest, 
since the construction techniques and materials used at the time were guarantors against any possibility of failure or instability phenomena.

The instability phenomena could occur in all types of structures except those subject to tension. Therefore, it can occur in elements subject to compression, flexion, torsion, shear, and in compound stress states. The instability occurs in a sudden and unpredictable way, without the possibility of reinforcing or decreasing loads.

However, the problem of instability entails very serious analytical difficulties, so recourse to calculation procedures that provide approximate solutions to the problem. Numerous studies analysed the problem; Aboudi, Gilat [9] studied the analogy between the equations for the analysis of instability in elastic structures and the equations of the wave propagation motion. Employing this analogy, the exact and approximate instability stress of continuous fiber composite laminated materials are established. With a certain variation of variables in these dispersion relations, the instability corresponding to the stresses can be determined.

Further studies concerned the problem of the instability of composite beam-columns and panels: Marouene et al. [10] analysed the instability behaviour of composite panels with variable stiffness, produced by the automated fiber positioning process (AFP). To minimize the occurrence of intrinsic defects such as gaps and overlaps, the so-called tow-drop method was used. It has been established that the tow-drop method has significantly improved the structural performance in terms of pre-buckling stiffness and the tensile strength, obviously keeping the geometric disturbances minimal.

Athhan [11] conducted studies on composite beams, observing the effects of load sequences, fiber orientation angles, boundary conditions and delamination modes on the critical loads of laminated beams. The results show that a reduction in critical loads occurs when the length of the delamination increases. In numerical analysis, the appropriate buckling load values of the laminated beams are obtained using a reduced elastic modulus for the contact elements in the region where delamination is induced. Cappello, Tumino [12] studied the buckling behaviour of flat laminates in composite material characterized by the presence of multiple delamination, subject to axial compression loads. The FEM method was used, conducting a both linear and non-linear analysis. The non-linear analysis considers large displacements and a contact constraint between the edges to prevent their interpenetration. The results were compared with those of analytical theories and with other numerical and experimental results found in the literature. It has been found that both the length and the positioning of the delamination and the packaging sequence of the laminae influence the critical load of the laminate.

Despite this, all the studies carried out to consider the problem of delamination because of the propagation of a detachment already present on the structural support.

Since FRP strips reinforcements are scarcely resistant to compression, attention is focused on this weakness. Slender beam-columns in no-tension homogeneous material and subjected to compression are considered, both in normal and FRP reinforced configurations. The global instability of the analysed model may occur accompanied by local instability of the reinforcement in the compressed area. This can lead to a considerable reduction in stiffness and to the loss of reinforcement effectiveness [13]. The choice of a non-tensile structural element simulates the behaviour of the most widespread materials in historic buildings such as masonry. For example, the vulnerability of masonry panels to out-of-plane stress often requires the application of reinforcement. A modern approach is represented by fiber-reinforced plastic composite materials (FRP).

This reinforcement provides the surfaces of the existing panel with the capacity to withstand tensile stress and, as a result, increases the panel's resistance to out-of-plane bending. The cyclicality and uncertainty of seismic action, the tension-free nature of masonry require the application of the reinforcement on both sided of the panel [14], [15]. The problem of buckling delamination becomes even more critical in cases where external composite strips are applied to both sides of the wall. An explanatory application is illustrated in Figure 1. 


\section{$\left.\right|_{\substack{\text { CIVIL } \\ \text { ENGINEERING } \\ \text { JOURNAL }}}$}

Article no. 26
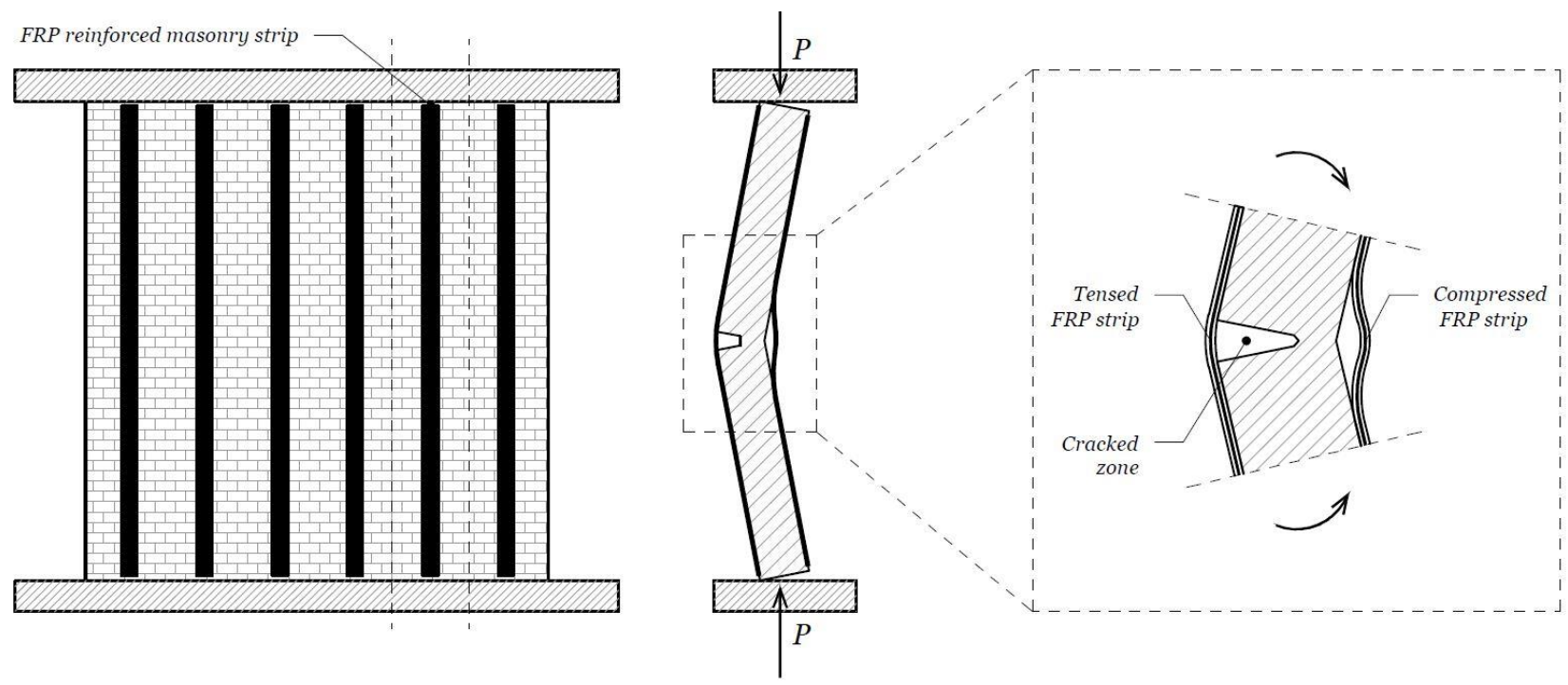

Fig. 1 - FRP strengthened masonry panel (example) and debonding mechanisms

Under the out-of-plane deflection of the reinforced panel (Figure 1), one layer of FRP is subjected to tension, but the other is subjected to compression. Under these conditions, the two reinforcement layers are subjected to tension and compression, respectively. At the same time, the increase in axial tension in the compressed FRP tape can also trigger a delamination process tension.

The problem of interfacial deboning is a fundamental problem in the structural performance of almost any type of composite or layered structure [16].

The present work aims to study the behaviour of a slender structural element subjected to axial loads, and to highlight the different behaviour of the reinforcements when they are stretched or compressed. The main objective is to provide a simplified method to predict delamination or loss of effectiveness of the reinforcement in the compressed region.

Analysing the state of art, this paper:

- Provides an analytical closed-form expression for the buckling delamination length;

- Validate the prediction of critical load for a prismatic compressed beam-column.

\section{BUCKLING ANALYSIS}

In this phase the general method of calculating the critical load for a beam-column hinged at the ends is illustrated; then the case of a beam-column composed of no-tension and brittle material (e.g. stone, marble) with eccentric load, which better approximates the common real cases, is analysed. Finally, the reinforcement layers are analysed.

A compressed beam-column with no-tension constitutive model may experience three stress regimes:

i. every cross-section is compressed;

ii. every cross-section is partially damaged;

iii. the beam-column is compressed at the ends and cracked in its remaining parts. In this study, the iii) phase is considered.

\section{Buckling analysis of a no-tensile structural element}

A beam-column element subject to axial compression could fail either by buckling or by reaching the maximum compression stress. The prediction of the critical load value obtained with the Euler formula (1), is valid only for very long and thin beam-columns without geometric imperfections 


$$
P_{e}=\frac{\pi^{2} E I}{l^{2}}
$$

A solution that well approximates the real case was provided by Yokel [17]. This model provides an approximate solution of the critical load for compressed prismatic elements made of materials with no tensile strength. Refer to the beam-column in a state of post-buckling equilibrium represented in Fig. 2 with compression load applied with eccentricity $t / 6 \leq e<t / 2$.

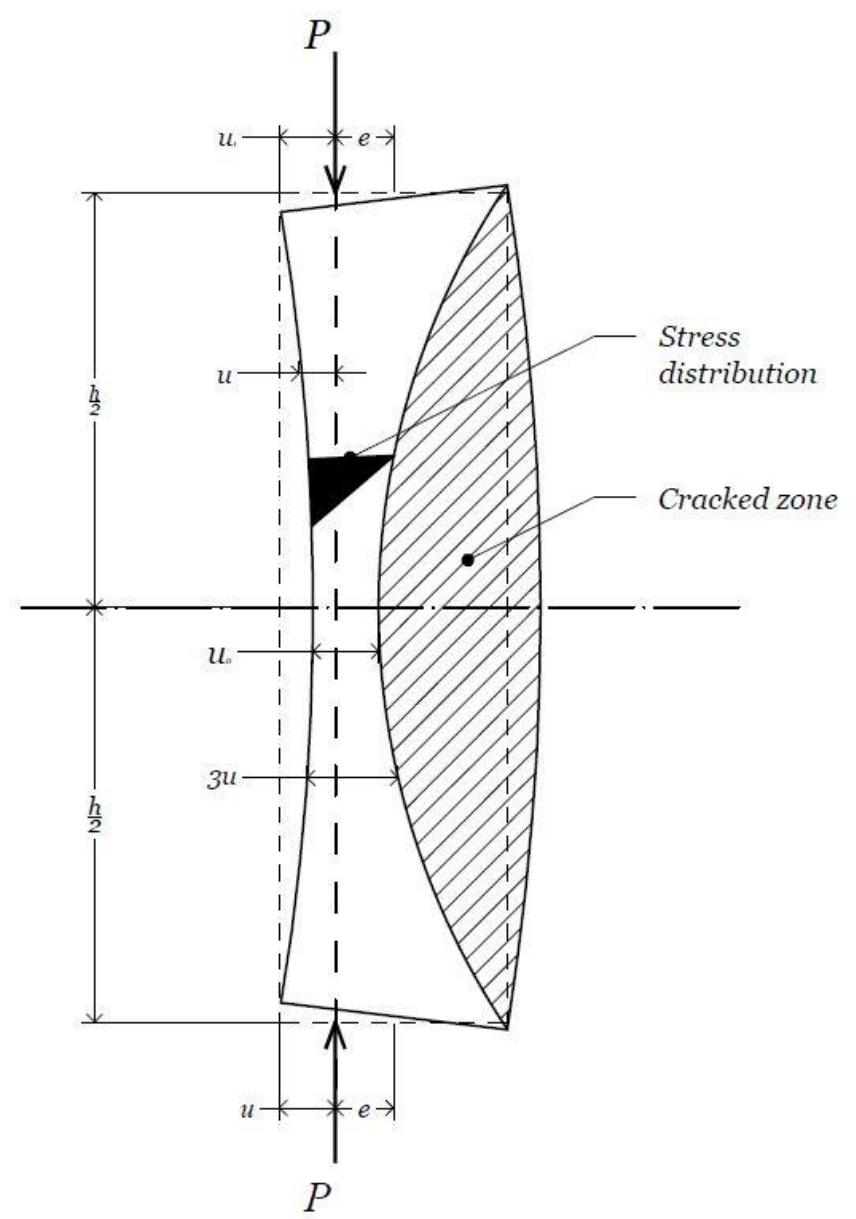

Fig. 2 - Cracked compressed beam-column with eccentric load

The dotted area represents the compressed area; the triangular shaded area represents the trend of the compression tensions in a generic section; $u$ represents the distance between the compressed edge of the beam-column and the load application line. The maximum value of $u$ ( $u 1$ ) is at the beam-column top, while the minimum value $(u 0)$ is in the middle, as shown in Figure 2. 


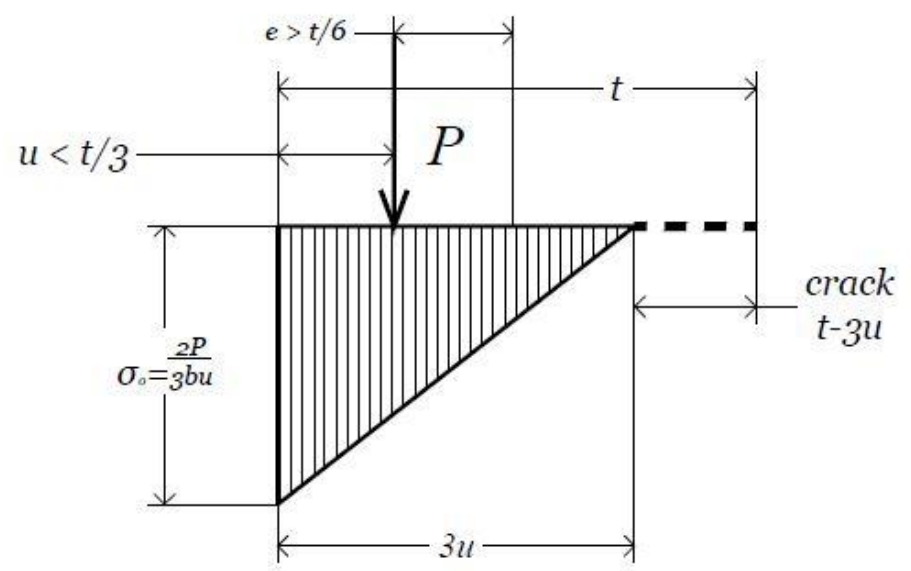

Fig. 3 - Stress distribution in the middle section

The maximum value of the compression tension could be expressed as follows:

$$
\sigma_{\max }=\frac{2 P}{3 b u_{0}}
$$

The value of the equivalent critical load is determined:

$$
P_{e c}=\frac{9}{4} \frac{E b u_{1}^{3}}{h^{2}}
$$

Yokel [17] determined with good approximation the critic load value:

$$
P_{c r}=0.285 P_{e c}
$$

That is:

$$
P_{c r}=0.64125 \frac{E b u_{1}^{3}}{h^{2}}
$$

The critical load value could be also approximated to:

$$
P_{c r}=8 \pi^{2}\left(\frac{1}{2}-\frac{e}{t}\right)^{3} \frac{E I_{0}}{h^{2}}
$$

Where $I_{0}$ represent the moment of inertia of non-cracked sections. For $e=0$, Equation 6 is the Euler formula.

\section{Analytical model of FRP reinforced beam-column}

The assumption that the material is elastic in compression and without any resistance in tension is postulated. A slender element is considered with a constant rectangular section and reinforced on the major faces with FRP strips applied longitudinally to the support, Figure 3 . As mentioned above, the instability of the support leads to distinguish a compressed and a tensed area.

Therefore, the reinforcement applied to the tensed area follows the deformation of the substrate. The reinforcement in the compressed area could be subject to delamination phenomena due to the high stress [7] that occurs at the interface of the two materials, which can lead to the propagation of micro-cracks present or to the formation of new ones.

\section{Pre-buckling phase}

In the loading phase before the critical load value, the beam-column only bears axial compression stresses (i) phase). The compression stress is given by the area density of the load on the overall section. Previous studies [18] illustrated how the behaviour of the instability of thin layers (e.g. FRP reinforcements) depends on the stiffness of the substrate and of the reinforcement itself. 


\section{Buckling phase - FRP stability contribution}

The beneficial contribution to the stability of the beam-column given by the reinforcement in the tensed area can be investigated using the elastic model of the beam-column on the Winkler elastic soil [19]. The conditions of instability of a beam-column of finite length with hinged ends (Figure 3) can be expressed by the following:

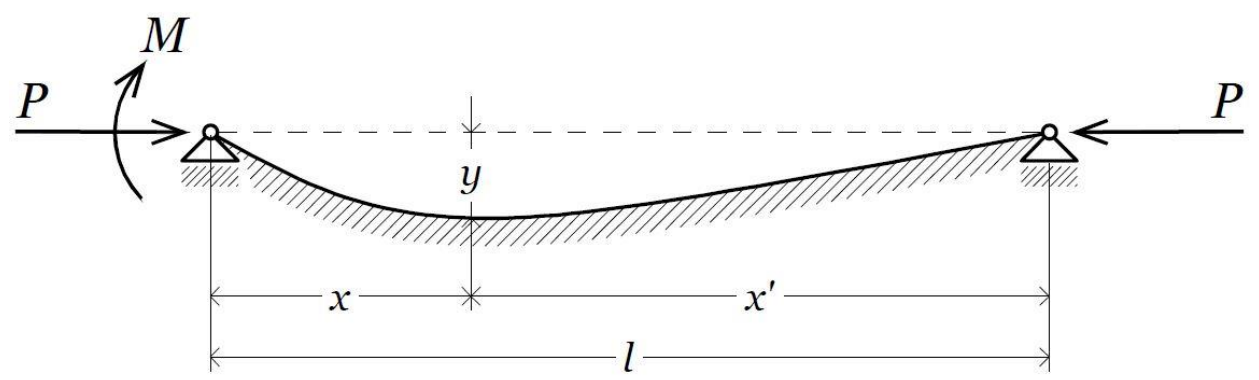

Fig. 2 - Static diagram of hinged beam-column on elastic soil

The + or - sign in the denominator correspond to a symmetrical or asymmetrical inflection respectively. When no moments are applied to the ends, the beam-column can have a deflection of finite value only if Equation 7 is cancelled.

This can only happen if $\alpha \beta=0$, which provides the value of the critical load as a solution:

$$
P_{c r}=2 \sqrt{k E I}
$$

Equivalent to the critical load for a beam-column of infinite length.

Since this condition does not consider the finite length of the beam-column, it can be stated that it is not the complete solution; therefore, other possibilities must be considered.

From the same denominator another condition is obtained:

$$
\cosh \beta l \pm \cos \alpha l=0
$$

Since $\cosh \beta l>1 \mathrm{e} \cos \alpha l<1$, this equation cannot be satisfied by real values of $\alpha \mathrm{e} \beta$, where:

$$
\alpha=\sqrt{\sqrt{\frac{k}{4 E I}}+\frac{P}{4 E I}} ; \quad \beta=\sqrt{\sqrt{\frac{k}{4 E I}}-\frac{P}{4 E I}}
$$

It should therefore be noted that the value of the critical load due to the instability of a hinged beam-column must be sought if $P_{c r}>2 \sqrt{k E I}$.

Considering thus:

where:

$$
\beta=i \bar{\beta}
$$

With these substitutions the following equation is obtained:

$$
\bar{\beta}=\sqrt{\frac{P}{4 E I}-\sqrt{\frac{k}{4 E I}}}
$$

$$
\cosh \bar{\beta} l \pm \cos \alpha l=0
$$

Which is satisfied by the following:

$$
(\alpha-\bar{\beta}) l=n \pi
$$

For odd values of $\mathrm{n}$ there is a positive sign in the penultimate equation; for even values, there is a negative sign. Substituting in the last one the expressions for $\alpha$ and $\beta$, we obtain the following formula for the critical load: 


$$
P_{c r}=n^{2} \frac{\pi^{2} E I}{l^{2}}+\frac{1}{n^{2}} \frac{k l^{2}}{\pi^{2}}
$$

Since in the specific case the first buckling mode is investigated, by setting $n=1$ the value of the critical load is obtained:

$k$ represents the FRP stiffness constant.

$$
P_{c r}=\frac{\pi^{2} E I}{l^{2}}+\frac{k l^{2}}{\pi^{2}}=P_{c r, E}+\frac{k l^{2}}{\pi^{2}}
$$

FRP reinforcement provides a beneficial effect to buckling, as the critical load value is increased by the quantity proportional to the characteristic constant of the reinforcement and to the length of the same. obtained:

Considering Equations 5 and 12, the reinforced beam-column governing equation is

$$
P_{c r}=0.64125 \frac{E b u_{1}^{3}}{h^{2}}+\frac{k l^{2}}{\pi^{2}}
$$

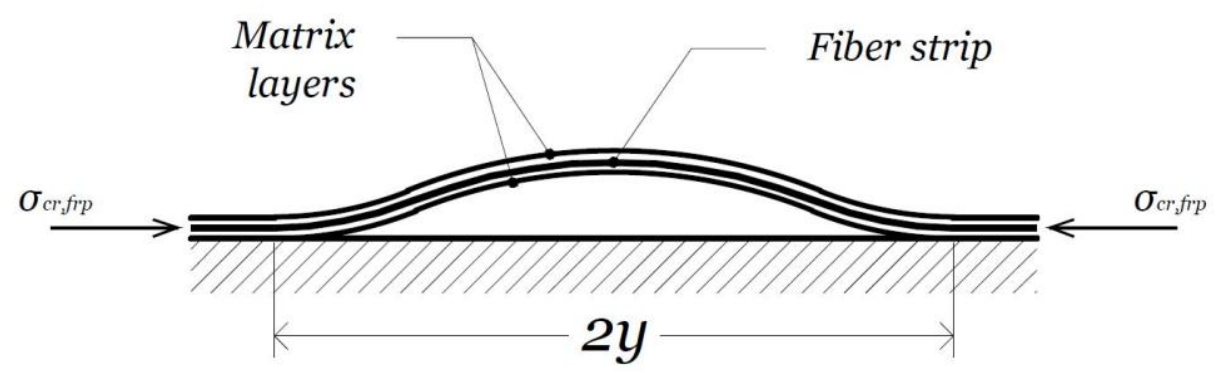

Fig. 3 - FRP buckling on compressed face

\section{Buckling phase - FRP buckling delamination}

As reported in previous works [13], in the case of a soft substrate, the phenomenon of wrinkling occurs in the external film; in the case of a rigid substrate, the substrate is delaminated (Figure 5). This phenomenon does not depend on the substrate, but only on the reinforcement and on the dimensions of the initial delamination [13].

In case of high compression stresses, reinforcement delamination could occur without the presence of cracks or initial cracks. The instability of a thin laminate could be solved as a classic problem of buckling a strip with clamped ends. The following critical stress is therefore obtained [13]:

$$
\sigma_{c r}=\frac{\pi^{2} E_{f r p}}{3\left(1-v^{2}\right)}\left(\frac{t_{f r p}}{2 y}\right)^{2}
$$

Where $E$ is the Young's modulus and $v$ is the Poisson's modulus, $t$ is the thickness of the reinforcement layer and $l$ is the delamination length. The deflection due to buckling is given by [13]:

$$
w=\frac{1}{2} w_{0}\left(1+\cos \frac{2 \pi x}{l}\right)
$$

Where $w_{0}$ is the maximum deflection, $l$ is the delamination length. From the expression of the generic deflection and through geometric considerations, the expression of the maximum deflection is obtained [13]:

$$
w_{0}^{2}=\frac{4}{\pi^{2}} \varepsilon_{c} l^{2}
$$

In the reinforced beam-column model, it is possible to consider - for the sake of simplicity - a linear distribution of the cracked areas according to the height previously illustrated in Fig.1. 
In the model of the reinforced beam-column, a linear distribution (Fig. 3) of the cracked sections can be considered for simplification as the height varies since $l \gg t$.

The linear stress distribution leads to define the equation of the neutral axis in this way:

$$
x(y)=\frac{2 y(t-3 u)}{h}+3 u
$$

The compression stress in the beam-column at a generic height $y$ is given by the following:

$$
\sigma(y)=\frac{2 P}{x(y) b}
$$

or:

$$
2 P=\sigma(y) \cdot x(y) \cdot b
$$

As the compression stress is equal to the critical stress, the reinforcement is delaminated. By equating equations $(14,17,19)$, it is possible to find the delamination position. Supposing $u_{1}=t / 3$, the following is obtained:

or:

$$
2 P_{c r}=\frac{\pi^{2} E_{f r p}}{3\left(1-v^{2}\right)}\left(\frac{t_{f r p}}{2 y}\right)^{2} \frac{2 y\left(t_{\text {beam }}-3 u\right)+3 u h}{h} b
$$

$$
P_{c r}=\frac{1}{24} \frac{\pi^{2}}{\left(1-v^{2}\right)} E_{f r p} \frac{t_{f r p}{ }^{2}}{y^{2}} \frac{2 y\left(t_{\text {beam }}-3 u\right)+3 u h}{h} b
$$

or:

from which:

$$
y^{2} \cdot P_{c r}=A \alpha \beta\left(2 y t_{b e a m}-6 u y+3 u h\right)
$$

$$
y^{2} P_{c r}-y\left(2 \gamma t_{b e a m}-6 u \gamma\right)-3 u h \gamma=0
$$

where:

$$
\begin{gathered}
A=\frac{1}{24} \frac{\pi^{2}}{\left(1-v^{2}\right)} ; \\
\alpha=\frac{b}{h} ; \\
\beta=E_{f r p} t_{f r p}^{2} ; \\
\gamma=A \alpha \beta
\end{gathered}
$$

Thus, the delamination half-length is:

$$
y=\frac{\left(2 \gamma t_{\text {beam }}-6 u \gamma\right) \pm \sqrt{\left(2 \gamma t_{\text {beam }}-6 u \gamma\right)^{2}+12 P_{c r} u \gamma h}}{2 P_{c r}}
$$

\section{CASE STUDY}

The aim of this study is to provide a simplified method to predict delamination or loss of effectiveness of the reinforcement itself during the buckling phenomenon.

In this section, a numerical application is illustrated. The case of the beam-column with hinged ends and reinforced on both the major faces with FRP - as in the formulation of the problem - is considered.

In analogy with the experimental campaign carried out in [20], the same brittle homogeneous beam-column and FRPs reinforcements are considered. Poisson ratio is set 0.37 for all reinforcement considered, as in its typical values. Materials mechanical and geometrical parameters are summarized in Table 1. Marble beam-column analysed in [20] are depicted in Fig. 6. Specimens with SRP/BFRP strips on both side surfaces - dimensions $300 \mathrm{~mm} \times 28 \mathrm{~mm}$ - were subjected to compression until the reinforced SRP/FRP strips on the compressed side of the specimen were delaminated. For both types of reinforcement, the marble surfaces were treated with a primer and 
then a two-component epoxy adhesive was used as a fibre matrix to ensure the adhesion to the substrate.

The test setup used during the tests included: cell loading to measure compressive load, P; three LVDTs to record lateral deflections; one LVDT to measure vertical displacements; two strain gauges (E1-E2) in the middle of the specimen span on the lateral surface to measure the deformation of SRP/BFRP strips under compression.

Tab. 1 - Mechanical parameters

\begin{tabular}{|c|c|c|c|c|c|c|c|c|c|c|c|}
\hline \multicolumn{4}{|c|}{ MARBLE } & \multicolumn{4}{|c|}{ SRP $^{*}$} & \multicolumn{4}{|c|}{ BFRP $^{*}$} \\
\hline $\begin{array}{l}\text { tbeam- } \\
\text { column } \\
(\mathrm{mm})\end{array}$ & $\begin{array}{l}\text { bbeam- } \\
\text { column } \\
(\mathrm{mm})\end{array}$ & $\begin{array}{l}h_{\text {beam- }} \\
\text { column } \\
(\mathrm{mm})\end{array}$ & $\begin{array}{c}\text { Ebeam-column } \\
\left(\mathrm{kN} / \mathrm{mm}^{2}\right)\end{array}$ & $\begin{array}{c}\text { trpp } \\
(\mathrm{mm})\end{array}$ & $\begin{array}{l}\text { birp } \\
(\mathrm{mm})\end{array}$ & $\begin{array}{l}h_{\text {frp }} \\
(\mathrm{mm})\end{array}$ & $\begin{array}{c}\text { Efrp } \\
\left(\mathrm{kN} / \mathrm{mm}^{2}\right)\end{array}$ & $\begin{array}{c}\text { trpp } \\
(\mathrm{mm})\end{array}$ & $\begin{array}{l}b_{\text {frp }} \\
(\mathrm{mm})\end{array}$ & $\begin{array}{l}h_{\text {frp }} \\
(\mathrm{mm})\end{array}$ & $\begin{array}{c}E_{f r p} \\
\left(\mathrm{kN} / \mathrm{mm}^{2}\right)\end{array}$ \\
\hline 6 & 28 & 300 & 68.90 & 0.48 & 28 & 300 & $118^{*}$ & 0.14 & 28 & 300 & $100^{*}$ \\
\hline
\end{tabular}

*Provided by manufacturers.

Table 2 summarizes experimental results by compression tests on column specimens obtained by [20].

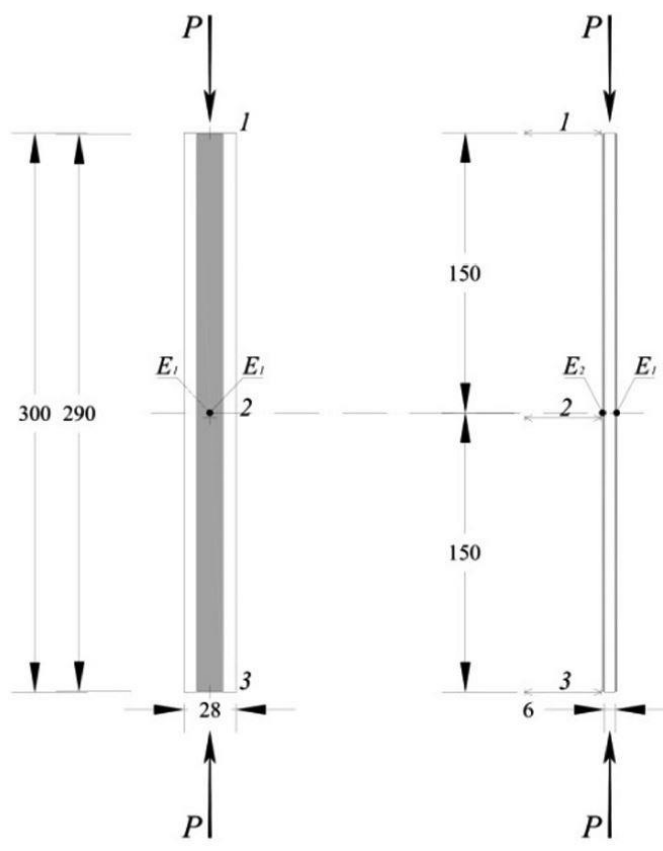

Fig. 4 - Specimens with SRP/BFRP strips under compression

Tab. 2 - Experimental results on beam-column specimens

\begin{tabular}{|c|c|c|}
\hline SPECIMEN & $\begin{array}{c}\text { TYPE OF } \\
\text { STRENGTHENING }\end{array}$ & $\begin{array}{c}\text { EXP. BUCKLING LOAD } \\
\text { (mean value) }\end{array}$ \\
\hline UMC & - & $4.56 \mathrm{kN}$ \\
\hline RMC 2 & SRP & $6.99 \mathrm{kN}$ \\
\hline RMC 3-4 & BFRP & $5.53 \mathrm{kN}$ \\
\hline
\end{tabular}


Once the mechanical and geometrical parameters of the reinforcement and critical load for reinforced beam-column configuration are known, it is possible to determine the experimental stiffness constant value from Equation 24 (Table 3).

Tab. 3 - Stiffness constant calculation

\begin{tabular}{|c|c|}
\hline $\begin{array}{c}\text { TYPE OF } \\
\text { STRENGTHENING }\end{array}$ & $\mathbf{k}\left(\mathbf{N} / \mathbf{m m}^{\mathbf{3}}\right)$ \\
\hline SRP & 0.7544 \\
\hline BFRP & 0.5944 \\
\hline
\end{tabular}

Once all parameters all well-defined, it is possible to determine the delamination length which occur in the FRP reinforcement layer as the critical stress is achieved. These lengths are $10.65 \mathrm{~mm}$ and $35.29 \mathrm{~mm}$ for BFRP and SRP reinforced beam-columns, respectively.

Obviously, the delamination lengths increase as the axial load increases until the specimen failure, as reported in [20]. This paper aims to determine the delamination length in the FRP reinforcement layer at the exact moment when the beam-column undergoes buckling.

\section{NUMERICAL APPLICATIONS}

In this section, a numerical application is illustrated. The case of the hinged beam-column and reinforced on both the major faces with FRP - as in the formulation of the problem - is considered.

Different beam-column lengths are considered, from 200 to $425 \mathrm{~mm}$. The beam-column is assumed made of marble material of fixed dimensions (Table 4).

Tab. 4 - Mechanical parameters for numerical application

\begin{tabular}{|c|c|c|c|c|c|c|c|}
\hline $\begin{array}{l}t_{\text {beam- }} \\
\text { column } \\
(\mathrm{mm})\end{array}$ & $\begin{array}{c}\text { tfrp } \\
(\mathrm{mm})\end{array}$ & $\begin{array}{l}\text { b beam- } \\
\text { column } \\
(\mathrm{mm})\end{array}$ & $\begin{array}{c}h_{\text {beam-column }} \\
\text { (mm) }\end{array}$ & $\begin{array}{c}\text { Ebeam-column } \\
\left(\mathrm{kN} / \mathrm{mm}^{2}\right)\end{array}$ & $\begin{array}{c}E_{f r p} \\
\left(k N / m m^{2}\right)\end{array}$ & $\begin{array}{l}v \\
(-)\end{array}$ & $\begin{array}{c}u \\
(m m)\end{array}$ \\
\hline 6 & 0.14 or 0.48 & 28 & $\begin{array}{c}\text { from } \\
200 \text { to } 425\end{array}$ & 68.90 & 100 or 118 & 0.37 & 2 \\
\hline
\end{tabular}

Once the mechanical and geometrical parameters of the reinforcement type are known, it is possible to determine the value of the critical stress and delamination, as illustrated in Table 5. 
Tab. 5 - BFRP reinforcement parameter calculation

\begin{tabular}{|c|c|c|c|c|c|}
\hline $\begin{array}{c}\boldsymbol{h} \\
(\mathbf{m m})\end{array}$ & $\begin{array}{c}\boldsymbol{\alpha} \\
(-)\end{array}$ & $\begin{array}{c}\boldsymbol{\beta} \\
(-)\end{array}$ & $\begin{array}{c}\boldsymbol{\gamma} \\
(\mathbf{m m})\end{array}$ & $\begin{array}{c}\boldsymbol{\sigma}_{\text {cr,frp }} \\
\left(\mathbf{N} / \mathbf{m m}^{2}\right)\end{array}$ & $\begin{array}{c}\boldsymbol{y} / \mathbf{h} \\
(-)\end{array}$ \\
\hline 200 & 0.14 & 1.96 & 0.13 & 31.62 & 0.0769 \\
\hline 225 & 0.14 & 1.96 & 0.13 & 34.33 & 0.0656 \\
\hline 250 & 0.12 & 1.96 & 0.12 & 42.02 & 0.0533 \\
\hline 275 & 0.11 & 1.96 & 0.10 & 50.71 & 0.0441 \\
\hline 300 & 0.10 & 1.96 & 0.10 & 60.35 & 0.0371 \\
\hline 325 & 0.09 & 1.96 & 0.09 & 70.93 & 0.0316 \\
\hline 350 & 0.09 & 1.96 & 0.08 & 82.44 & 0.0272 \\
\hline 375 & 0.08 & 1.96 & 0.07 & 94.88 & 0.0237 \\
\hline 400 & 0.07 & 1.96 & 0.07 & 108.23 & 0.0208 \\
\hline 425 & 0.07 & 1.96 & 0.07 & 122.49 & 0.0184 \\
\hline
\end{tabular}

Table 6 shows the parameters obtained for SRP reinforced beam-columns.

Tab. 6 - SRP reinforcement parameter calculation

\begin{tabular}{|c|c|c|c|c|c|}
\hline $\begin{array}{c}\boldsymbol{h} \\
(\mathbf{m m})\end{array}$ & $\begin{array}{c}\boldsymbol{\beta} \\
(-)\end{array}$ & $\begin{array}{c}\boldsymbol{\beta} \\
(-)\end{array}$ & $\begin{array}{c}\boldsymbol{\gamma} \\
(\mathbf{m m})\end{array}$ & $\begin{array}{c}\boldsymbol{\sigma}_{\text {cr,frp }} \\
\left(\mathbf{N} / \mathbf{m m}^{2}\right)\end{array}$ & $\begin{array}{c}\boldsymbol{y} \mathbf{h} \\
(-)\end{array}$ \\
\hline 200 & 0.14 & 27,19 & 1,81 & 39,35 & 0,2566 \\
\hline 225 & 0.14 & 27.19 & 1.81 & 43.02 & 0.2181 \\
\hline 250 & 0.12 & 27.19 & 1.61 & 52.89 & 0.1771 \\
\hline 275 & 0.11 & 27.19 & 1.45 & 63.98 & 0.1463 \\
\hline 300 & 0.10 & 27.19 & 1.32 & 76.28 & 0.1229 \\
\hline 325 & 0.09 & 27.19 & 1.21 & 89.76 & 0.1045 \\
\hline 350 & 0.09 & 27.19 & 1.12 & 104.41 & 0.0900 \\
\hline 375 & 0.08 & 27.19 & 1.04 & 120.23 & 0.0783 \\
\hline 400 & 0.07 & 27.19 & 0.97 & 137.20 & 0.0687 \\
\hline 425 & 0.07 & 27.19 & 0.91 & 155.32 & 0.0608 \\
\hline
\end{tabular}

It is noted that the critical stress required to start the delamination decreases as the length of the beam-column increases. The graph in Figure 5 shows the trend of the delamination length percentage on total length with respect to the variation of the beam-column and reinforcement length. 


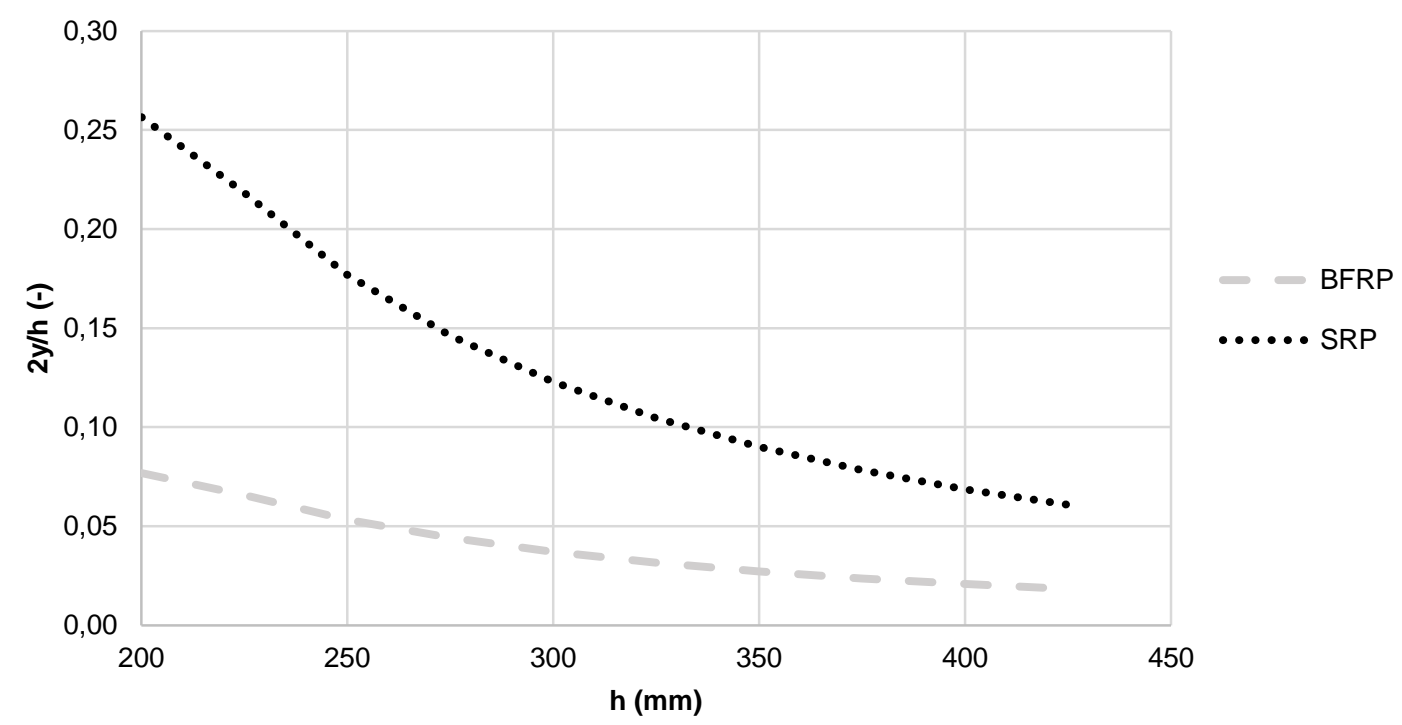

Figure 5 - Delamination percentage on total beam-column length

\section{CONCLUSIONS}

Since FRP strips reinforcements are scarcely resistant to compression, the present paper focuses its attention on this characteristic. Slender beam-columns in homogeneous linear brittle notension material and subjected to compression, both normal and FRP-reinforced conditions are considered. The problem of the stability of a no-tensile structural element and reinforced with FRP is analytically analysed, according to the elastic theory. The aim of this work is to highlight the different behaviour of reinforcements when they are tense or compressed, and to provide a simplified method to predict detachment or loss of effectiveness of the reinforcement itself. In particular, the reinforcement layer applied in the tense face of the specimens showed a stability contribution, while the one applied in the opposite side underwent buckling delamination. If the geometric and mechanical parameters of materials are known, it is possible to estimate the critical load of the entire beam-column. It is therefore possible to establish the delamination length of the compressed reinforcement at the critical load and therefore of the critical tension.

The results obtained make it possible to estimate the contribution to stability resulting from the use of FRP reinforcements. The study presented analyses the contribution of BFRP and SRP reinforcements. It is observed that increasing the height of the structural element considered, the percentage of delamination on the total length of the reinforcement decreases according to a nonlinear trend. In the case of the BFRP reinforcement, the critical tension necessary to trigger delamination - for a $400 \mathrm{~mm}$ high column - triples its value with respect to the same $200 \mathrm{~mm}$ high structural element. The same phenomenon could be observed for SRP reinforcement.

The results obtained by means of hypotheses and simplified theories make it possible to estimate the value of the critical load at which delamination of the compressed reinforcement occurs, which loses its effectiveness for low load values. A further result is consequently that of providing a method for estimating the critical load of the reinforced beam-column, developing a useful, practical, and rapid instrument in the design phase. 


\section{REFERENCES}

[1] T. C. Triantafillou, "Strengthening of Historic Structures with Advanced Composites: A Review," in Recent Advances in Composite Materials, Dordrecht: Springer Netherlands, 2003, pp. 337-344.

[2] T. C. Triantafillou, "Composites: a new possibility for the shear strengthening of concrete, masonry and wood," Compos. Sci. Technol., vol. 58, no. 8, pp. 1285-1295, Aug. 1998.

[3] C. Faella, E. Martinelli, G. Camorani, M. A. Aiello, F. Micelli, and E. Nigro, "Masonry columns confined by composite materials: Design formulae," Compos. Part B Eng., vol. 42, no. 4, pp. 705-716, Jun. 2011.

[4] C. Faella et al., "Masonry columns confined by composite materials: Experimental investigation," Compos. Part B Eng., vol. 42, no. 4, pp. 692-704, Jun. 2011.

[5] L. Ascione, L. Feo, and F. Fraternali, "Load carrying capacity of 2D FRP/strengthened masonry structures," Compos. Part B Eng., vol. 36, no. 8, pp. 619-626, Dec. 2005.

[6] M. Corradi, A. Borri, and A. Vignoli, "Strengthening techniques tested on masonry structures struck by the Umbria-Marche earthquake of 1997-1998," Constr. Build. Mater., vol. 16, no. 4, pp. 229-239, Jun. 2002.

[7] M. R. Valluzzi, D. Tinazzi, and C. Modena, "Shear behavior of masonry panels strengthened by FRP laminates," Constr. Build. Mater., vol. 16, no. 7, pp. 409-416, 2002.

[8] D. Bruno and F. Greco, "An asymptotic analysis of delamination buckling and growth in layered plates," Int. J. Solids Struct., vol. 37, no. 43, pp. 6239-6276, Oct. 2000.

[9] J. Aboudi and R. Gilat, "Buckling analysis of fibers in composite materials by wave propagation analogy," Int. J. Solids Struct., vol. 43, no. 17, pp. 5168-5181, Aug. 2006.

[10] A. Marouene, R. Boukhili, J. Chen, and A. Yousefpour, "Buckling behavior of variable-stiffness composite laminates manufactured by the tow-drop method," Compos. Struct., vol. 139, pp. 243-253, Apr. 2016.

[11] G. Atlihan, "Buckling analysis of delaminated composite beams," Indian J. Eng. Mater. Sci., vol. 20, no. 4, pp. 276-282, 2013.

[12] D. Tumino, F. Cappello, and D. Rocco, "3D Buckling Analysis of Multidelaminated Composite Specimens," Sci. Eng. Compos. Mater., vol. 14, no. 3, Jan. 2007.

[13] L. M. Kachanov, "Delamination Buckling," 1988, pp. 19-56.

[14] A. Gawandi, L. A. Carlsson, T. A. Bogetti, and J. W. Gillespie, "Mechanics of discontinuous ceramic tile core sandwich structure: Influence of thermal and interlaminar stresses," Compos. Struct., vol. 92, no. 1, pp. 164-172, Jan. 2010.

[15] O. Rabinovitch and E. Hamed, "Bending Behavior of Sandwich Panels with a 'Soft' Core and Embedded Rigid Inserts," in Sandwich Structures 7: Advancing with Sandwich Structures and Materials, Berlin/Heidelberg: Springer-Verlag, pp. 261-270.

[16] J. W. Hutchinson and Z. Suo, "Mixed Mode Cracking in Layered Materials," 1991, pp. 63-191.

[17] F. Y. Yokel, "Stability and capacity of members with no tensile strength," ASCE J. Struct. Div., vol. 97, pp. 1913-1926, 1971.

[18] H. Mei, R. Huang, J. Y. Chung, C. M. Stafford, and H.-H. Yu, "Buckling modes of elastic thin films on elastic substrates," Appl. Phys. Lett., vol. 90, no. 15, p. 151902 , Apr. 2007.

[19] M. Hetényi, Beams on Elastic Foundation: Theory with Applications in the Fields of Civil and Mechanical Engineering. Ann Arbor: University of Michigan Press, 1946.

[20] R. Capozucca, E. Magagnini, and M. V. Vecchietti, "Delamination Buckling of FRP: Experimental Tests and Theoretical Model," 2020, pp. 753-766. 